they were competent? - as against objectively: What is in their best interests?), and then the question of who should make these decisions for them (family, ethics committee, judge, patient-appointed proxy?). Finally, there is a chapter about the special case of 'defective infants'.

The great merit of this book is its deceptive simplicity. Starting with such disparate leading cases as Quinlan, Conroy, and Saikewicz, Cantor begins by tracing the common thread of respect for the autonomy of the patient, in fact derived from one of the main traditions of the English common law (in Sidaway, our own courts preferred to follow a subsidiary, more paternalistic, one). From a complex tangle of dozens of other cases, he then succeeds in extracting a set of rational and intelligible principles, critically analysed, leading to guidelines for the future work of US courts and legislatures.

For anyone - lawyer, ethicist, or health practitioner - seeking clarification in this field, this is therefore a most commendable book. Its single lacuna is one expressly disclaimed in the Introduction: the borderline between competent and incompetent patients. Unlike the clients of lawyers, most patients of most doctors are ill, and some are very ill indeed. Even if they seem to be still in possession of their rational faculties, there is often reason to wonder how much they have taken in of what they have been told, how much they still remember even after only a few hours, and how much the rationality of their judgement will be afflicted by the powerful emotions released by their illness, its diagnosis, and the choices they are being offered. Yet autonomy, self-determination, and the rightsregarding model all presuppose patients at least capable of making rational judgements if they so wish.

Perhaps this could be the subject of Professor Cantor's next book.

PAUL SIEGHART 6 Gray's Inn Square, London WCIR 5AZ

\section{Ethical, Legal and Policy Issues Pertaining to Solid Organ Procurement}

The Hastings Center, 25 pages, New York, free while stocks last, The Hasting center, 1985
This short monograph was published by The Hastings Center in the United States. The center was founded in 1969 , in its own words, to 'shed light on ethical issues raised by advances in health care and to encourage informed and articulate debate about these issues'.

This report on organ transplantation was a project organised by the center under the direction of Arthur L Caplan and Ronald Bayer, assisted by a distinguished four-person panel. The report followed a series of meetings at the center, at which presentations were received from invited experts. The exercise was supported with a grant from The Health Services Improvement Fund, a foundation sponsored by Blue Cross and Blue Shield Insurance Companies.

Despite its title, the monograph is essentially a well-worded proposal for the revision of the current system for procuring organs in the United States with advocacy for so-called 'weak required request' policies. 'Weak required request' does not require each individual to state his or her intention as to organ donation. Individuals are free to choose to indicate their preference via a donor card or other written directive or not at all. However, under this kind of system, health care professionals are required to enquire of available family members or guardians whether the deceased person expressed a written preference for donation. If there is no evidence of such an intention, the health care professional is required to ask the next of kin about organ donation at the time death is pronounced.

Early in the report there are some tantalising references to the ethical issues that surround organ donation, but unfortunately, these are never fully explored. The authors include tw/o rather good quotations from Professor William May and Dr Leon Kass, which highlight some of the ethical problems surrounding organ transplanation and disappointingly leave it at that.

'We, ... with our dissection of cadavers, organ transplantation, cosmetic surgery ... and other practices and beliefs that insist on our independence and autonomy, live more and wholly for the here and now, subjugating everything we can to the exercise of our wills, with little respect for the nature and meaning of bodily life We expend enormous energy and vast sums of money to preserve and prolong bodily life, but, ironically, in the process bodily life is stripped of its gravity and much of its dignity' (1).
Perhaps debates about the morality of organ transplantation and the different methods for harvesting tissues are redundant. As the report points out, there is wide acceptance amongst the general public for these procedures. In 1983, the National Kidney Foundation in the United States commissioned the Gallup organisation to conduct a survey of public attitudes towards organ donation. The survey revealed that 93 per cent of the American population was aware of the need for organ transplants, and 83 per cent of those surveyed said they would be likely to donate 'a loved one's' organs if asked to do so. These findings have been subsequently confirmed by other surveys. What there may still be room for debate about is the system of 'presumed consent' for organ donation which operates in Austria, Denmark, Poland, Switzerland and France. Under this system, organ procurement is permitted to proceed in the absence of a prior objection from the deceased. However, there is no evidence that such legislation has improved the harvesting of organs for transplanation. The report criticises any moves to introduce this system to the United States because it challenges the rights of the individual to decide the fate of his or her body, enshrined in the 'Uniform Anatomical Gift Act' of July 30, 1968. However, the conflict between the rights of the individual over the disposition of his or her body after death and the needs of individuals who require transplants is not discussed.

The value of this report is that it provides sound background reading for anyone interested in the legal and policy issues pertaining to solid organ procurement in the United States. The history of legislation, current status of organ recovery in America, and the different methods for improving the yield of solid organs for transplantation are well covered. The problem of obtaining organs for transplantation is very much in the minds of health policymakers, both here and in the United States and it is a subject that we will be hearing much of in the near future; this Hastings Center report is a useful introduction to this problem.

\section{Reference}

(1) Kass L R. Toward a more natural science: biology and human affairs. New York: The Free Press, 1985.

S CHALLAH

Director, European Dialysis and Transplant Association Registry, St Thomas's Hospital, London 